\title{
Forecasting Produksi PT Pupuk Kujang untuk Mengatasi Penumpukan Persediaan Produk Jadi
}

\author{
Chintia Tanjung Kumala, Felix Surjadi, Frieska Junnianty Pelly, Rizal Ardi Patanroi \\ School of Business and Economics Universitas Prasetiya Mulya \\ JL. RA. Kartini (TB Simatupang), Cilandak Barat Jakarta Selatan, Jakarta 12430 Indonesia.
}

*. Corresponding Author: chintiatanjungkumala@gmail.com

\begin{tabular}{|c|c|}
\hline ABSTRACT & ARTICLE INFO \\
\hline $\begin{array}{l}\text { Fertilizer is one of the most important factors in Indonesian } \\
\text { agriculture that can support plant growth. In rice crop, the } \\
\text { commonly used fertilizer is NPK fertilizer. However, NPK fertilizers } \\
\text { have easy-to-clot properties and should be placed indoor. } \\
\text { Particularly in PT Pupuk Kujang, there is a problem of stacking up } \\
\text { NPK fertilizer caused by less inventory capacity than production } \\
\text { amount. Forecasting methods, such as simple moving average, can } \\
\text { prevent the occurrence of such problem. By using a simple moving } \\
\text { average per two months for percentage of production and } \\
\text { continued with normalization in } 2016 \text { production data, the actual } \\
\text { projection deviation in } 2017 \text { is } 3.52 \% \text {. }\end{array}$ & $\begin{array}{l}\text { Keywords: NPK fertilizer, PT Pupuk } \\
\text { Kujang, scheduling, inventory, } \\
\text { production }\end{array}$ \\
\hline ABSTRAK & \\
\hline $\begin{array}{l}\text { Pupuk merupakan salah satu faktor terpenting dalam pertanian } \\
\text { Indonesia yang dapat mendukung pertumbuhan tanaman. Pada } \\
\text { tanaman padi, pupuk yang biasa digunakan adalah pupuk NPK. } \\
\text { Namun, pupuk NPK memiliki sifat mudah menggumpal sehingga } \\
\text { harus ditempatkan dalam ruangan tertutup. Khususnya di PT } \\
\text { Pupuk Kujang, terjadi masalah penumpukan pupuk NPK yang } \\
\text { disebabkan oleh kapasitas penyimpanan produk jadi lebih kecil } \\
\text { dibandingkan jumlah produksi. Metode forecasting, seperti simple } \\
\text { moving average, dapat mencegah terjadinya masalah tersebut. } \\
\text { Dengan menggunakan simple moving average per dua bulan pada } \\
\text { persentase produksi dan dilanjutkan dengan normalisasi pada } \\
\text { tahun 2016, simpangan antara proyeksi dengan data aktual tahun } \\
2017 \text { adalah sebesar 3,52\%. }\end{array}$ & $\begin{array}{l}\text { Kata kunci: pupuk NPK, PT Pupuk } \\
\text { Kujang, penjadwalan, persediaan, } \\
\text { produksi }\end{array}$ \\
\hline
\end{tabular}




\section{PENDAHULUAN}

Indonesia merupakan negara agraris dimana sebagian besar penduduk Indonesia memiliki mata pencaharian di dalam sektor pertanian khususnya untuk pertanian tanaman padi. Untuk mendukung lancarnya proses produksi pada sektor pertanian, salah satu alat yang wajib digunakan merupakan pupuk. Pupuk terbagi menjadi dua golongan yaitu pupuk organik dan anorganik, akan tetapi jenis pupuk yang sering digunakan dalam sektor pertanian ini adalah pupuk anorganik. Berdasarkan Permentan Nomor 47/Permentan/SR.310/12/2017, jenis-jenis pupuk anorganik subsidi yang diberikan kepada petani adalah Urea, NPK, ZA dan SP-36.

Saat ini, seperti yang tertera pada Peraturan Menteri Pertanian Nomor 40/Permentan/OT.140/4/2007 tentang Rekomendasi Pemupukan N, P, dan K pada Padi

Sawah Spesifik Lokasi, pemerintah mendorong para petani padi untuk menggunakan pupuk NPK sebagai pengganti pupuk urea yang biasa digunakan oleh petani padi di Indonesia. Pupuk NPK memiliki karakteristik sangat sensitif terhadap kelembaban udara. Apabila tempat penyimpanan pupuk NPK tersebut sangat lembab maka pupuk NPK akan terjadi penggumpalan pada pupuk NPK tersebut. Dikarenakan oleh karakteristik NPK tersebut, perusahaan harus menyimpan pupuk NPK di dalam ruangan tertutup agar tidak terjadi penggumpalan.

Salah satu masalah yang sering terjadi pada perusahaan pupuk NPK adalah menumpuknya produk jadi yang dapat mengakibatkan kerugian pada perusahaan, hal ini terjadi dikarenakan oleh beberapa hal. Pertama, adanya Peraturan Menteri Pertanian tentang Kebutuhan dan Harga Eceran Tertinggi Pupuk Bersubsidi untuk Sektor Pertanian yang telah menetapkan jumlah produksi setiap perusahaan pupuk di Indonesia setiap tahunnya sehingga perusahaan harus memenuhi target tersebut. Berdasarkan Permentan Nomor

47/Permentan/SR.310/12/2017, seperti yang dapat dilihat pada RKAP PT Pupuk Kujang, bahwa target produksi untuk tahun 2017 telah ditetapkan sebesar 165.000 ton . Akan tetapi, jika hal ini tidak didukung dengan kapasitas penyimpanan produk jadi yang memadai, maka akan terjadi penumpukan produk jadi. Kedua, jumlah permintaan terhadap pupuk berfluktuasi 
yang diakibatkan dari siklus penanaman tanaman padi yang semakin tidak teratur dan secara musiman. Penumpukan yang terjadi pada inventori perusahaan ini tidak akan menjadi masalah besar apabila jumlah produk jadi yang diproduksi tidak melebihi total kapasitas penyimpanan inventori yang dimiliki oleh perusahaan.

Mengangkat dari masalah penumpukan inventori pada perusahaan pupuk, artikel ini akan membahas tentang penjadwalan proses produksi khususnya pada perusahaan pupuk PT Pupuk Kujang dengan research question sebagai berikut "Bagaimana melakukan forecasting data produksi untuk mengatasi masalah penumpukan inventori dalam perusahaan pupuk?".

\section{TINJAUAN PUSTAKA}

\section{Forecasting}

Pada produk yang bersifat musiman diperlukan prediksi produksi yang sesuai dengan data historis. Forecasting adalah proses memprediksi masa depan berdasarkan data di masa sekarang dan di masa lampau. Proses ini biasanya dilakukan dengan menganalisis tren dari data yang ada. Dalam berbisnis, perusahaan dapat melakukan forecasting terhadap permintaan pelanggannya sehingga inventaris, biaya keusangan, dan potensi kerugian akibat kehabisan stok produk dapat diminimalisasikan (Jain dan Malehorn, 2006). Salah satu model atau teknik forecasting yang banyak dilakukan dalam bidang teknik, pertanian, kedokteran ekonomi, dan geofisik adalah analisis deret berkala atau time series (Aprilia, 2016).

Berdasarkan Chambers, Mullick, dan Smith (1971), ada tiga tipe forecasting: teknik kualitatif (qualitative techniques ), analisis dan proyeksi deret berkala ( time series analysis and projection), dan model kausal ( causal models ). Teknik kualitatif menggunakan data kualitatif seperti pendapat ahli, informasi tentang peristiwa-peristiwa khusus, dan mungkin dapat atau tidak melibatkan data masa lalu. Sedangkan di sisi lain, analisis dan proyeksi 
deret berkala berfokus sepenuhnya pada pola data dan bergantung pada data historis. Tipe forecasting model kausal menggunakan informasi spesifik tentang hubungan antara elemen sistem serta peristiwa khusus secara normal ke dalam analisis data.

Terdapat lima metode forecasting yang dapat digunakan dalam analisis deret berkala, yaitu moving average, exponential smoothing, Box-Jenkins, X-11, dan trend projections . Pada metode moving average dan exponential smoothing, minimum jumlah data yang dibutuhkan adalah sebanyak 24 data dalam dua tahun (dengan data per bulan). Pada metode Box-Jenkins, minimum data yang dibutuhkan juga sama namun metode ini menggunakan model matematika dalam analisa datanya. Pada metode X-11 dan trend projections, minimum data yang dibutuhkan lebih banyak lagi, yakni tiga dan lima tahun (36 dan 60 data) secara berturut-turut. Sebagai tambahan, menurut Raihan et. al. (2016), metode exponential smoothing adalah metode forecasting yang paling banyak digunakan.

\section{The Winters Exponential Smoothing Procedure for a Seasonal Model}

Berdasarkan penelitian yang dilakukan oleh Ariyanto et. al. (2017), metode exponential smoothing dapat digunakan untuk meramalkan produksi tanaman pangan seperti padi, jagung, kedelai, ubi kayu, ubi jalar, kacang tanah dan kacang hijau. Metode ini sangat cocok untuk peramalan jangka pendek dan menengah. Peramalan untuk jangka waktu pendek dapat dilakukan dalam kurun waktu singkat (hari, minggu, dan bulan). Sedangkan peramalan dalam jangka waktu menengah dilakukan dalam periode satu sampai dua tahun mendatang dan peramalan dalam jangka waktu panjang dilakukan dalam waktu lebih dari dua tahun mendatang (Montgomery et. al., 2008).

Menurut Nahmias dan Olsen (2015), model Winters Exponential Smoothing Procedure dapat digunakan untuk menentukan demand pattern yang terjadi secara musiman. 
Forecasting dapat ditentukan per periode dan pada umumnya, periode forecasting adalah per satu bulan.

Musim diasumsikan sebagai lamanya periode $\mathrm{P}$, dan biasanya untuk annual season, angka $\mathrm{P}$ adalah 12 yang merupakan indikasi dari interval per bulan. Model musiman ini juga dapat digunakan untuk forecast secara mingguan atau bahkan harian. Dalam model ini, metode ratio to moving average juga digunakan untuk menentukan trend dari perubahan-perubahan pada periode sejarah. Namun, jika periode sejarah yang digunakan terlalu banyak, hal ini akan mengakibatkan trend yang terbentuk tidak mencerminkan keadaan saat ini dan terlebih lagi keadaan yang akan mendatang. Ada tiga langkah yang digunakan dalam model ini:

1. Tingkat perkiraan awal (termasuk trend) pada setiap periode sejarah, 2 . Memperkirakan faktor musiman, dan

3. Estimasi ao dan $\mathrm{b}_{0}$ (level dan trend data pada periode 0$)$.

Pada tahap pertama, perkiraan seasonal demand pattern dapat ditentukan menggunakan periodical moving totals dan moving average. Standar periodical moving average akan menghasilkan garis trend yang terletak pada dua periode, namun akan menjadi tidak tepat jika digunakan untuk lebih dari 2 periode. Maka dari itu, metode periodical moving totals dapat digunakan terlebih dahulu agar hasilnya lebih efisien.

Pada tahap kedua, seasonal factors digunakan untuk menentukan tingkat dari demand. Faktor ini digunakan untuk mengurangi efek random yang ada dalam data. Pada tahap terakhir, estimasi nilai a 0 dan $\mathrm{b}_{0}$ digunakan untuk menentukan nilai forecasting dalam bentuk unit dengan menggunakan rumus sebagai berikut: 


$$
x_{t}=(+a b) F_{t}
$$

where, $x_{t}=$ forecasting

value $a=$ the level $b$

$=$ the linear trend

$F_{t}=$ a seasonal index (coefficient) appropriate for period $t$

\section{Simple Moving Average}

Simple moving average merupakan suatu metode untuk rata-rata dari deretan nilai pada sebuah grafik atau pun tabel selama periode waktu tertentu (Ellis dkk., 2005). Metode simple moving average dapat memberikan estimasi atas permintaan pada periode berikutnya (Heizer dan Render, 2014). Berikut merupakan rumus dari Simple Moving Average:

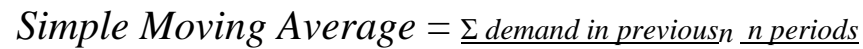

where, $n=$ the number of periods in the moving average -for example, 4, 5, or 6 months, respectively for a 4-, 5-, 6-period moving average

Setelah mendapatkan estimasi permintaan pada periode berikutnya, Mean Absolute Percentage Error (MAPE) dapat dihitung dengan cara:

$$
\text { MAPE }=\frac{1}{n} \sum\left\|_{t=1}^{n}{ }_{t=1} A_{t} A-{ }_{t} F_{t}\right\| \times 100 \%
$$

where, $n=$ number of data

$A=$ actual data $F=$ forecasting data 
MAPE dapat dijadikan sebagai indikator untuk meninjau performa suatu metode terhadap data yang diramalkan. Jika nilai MAPE semakin kecil, maka dapat diartikan bahwa metode yang dipakai semakin sesuai terhadap data yang diramalkan. Ketika nilai MAPE < 25\%, maka hasil dari data yang diramalkan dapat diterima secara memuaskan (Mainassy, 2014).

\section{Storage Management - Storage Facilities for Pesticide and Fertilizer}

Setelah melakukan proses produksi, perusahaan perlu melakukan manajemen penyimpanan yang baik untuk mencegah dan mengurangi risiko rusaknya persediaan produk jadi. Menurut Waskom dan Yergert (1994), dalam penyimpanan pestisida dan pupuk, terdapat beberapa hal yang perlu diperhatikan secara khusus, seperti:

- Pestisida dan pupuk disimpan dalam tempat yang terpisah.

- Fasilitas penyimpanan diberi label warning sign.

- Produk yang kering disimpan di atas produk cairan, atau di area yang berbeda.

- Tipe inventori dan jumlahnya dicatat (jika diperlukan, beri detail layout lokasi penyimpanan dan fasilitasnya).

- Area penyimpanan terletak dalam jarak aman dari sumur atau pun sumber air.

- Terdapat penyinaran, ventilasi, dan pemadam kebakaran yang cukup.

- Inspeksi rutin atas area penyimpanan untuk memeriksa apakah ada kebocoran atau produk yang tercecer. (Buat catatan atas inspeksi dan perbaikan yang dilakukan).

\section{METODOLOGI PENELITIAN}

Penelitian ini termasuk dalam kategori penelitian kuantitatif. Berdasarkan masalah yang ada, research question yang digunakan dalam artikel ini adalah sebagai berikut: "Bagaimana cara mengatasi masalah penumpukan inventori dalam perusahaan pupuk?" Penulis memilih perusahaan PT Pupuk Kujang sebagai objek penelitian yang mencerminkan langsung masalah tersebut. 
PT Pupuk Kujang sendiri merupakan anak usaha dari BUMN (Badan Usaha Milik Negara), PT Pupuk Indonesia yang bergerak di bidang industri pupuk nasional. Kegiatan-kegiatan yang dijalankan PT Pupuk Kujang adalah produksi, perdagangan, pemberian jasa dan usaha lainnya. Untuk mendukung kegiatan operasionalnya, perusahaan memiliki dua pabrik pupuk urea dengan total kapasitas produksi pupuk urea sebesar 1.140.000 ton/tahun, satu pabrik pupuk NPK Blending dengan kapasitas produksi sebesar 300.000 ton/tahun dan satu pabrik pupuk NPK Granular dengan kapasitas produksi sebesar 100.000 ton/tahun, serta perusahaan memiliki produk pupuk organik dengan merk "Petroganik" yang dihasilkan dari 26 pabrik yang dikelola oleh perusahaan. Sebanyak 26 pabrik tersebut berlokasi di beberapa daerah di Jawa Barat, di antaranya daerah Banjar, Garut dan Sumedang. Semua pabrik tersebut didirikan oleh pengusaha lokal dengan sistem lisensi merek. Total kapasitas produksi pupuk organik PT Pupuk Kujang saat ini adalah 20.000 ton/tahun.

Untuk mendapatkan data primer dilakukan pengamatan langsung ke lokasi pabrik dan gudang PT Pupuk Kujang pada 11 Desember 2017 dan melakukan wawancara dengan Pak Rhony, selaku Kepala Divisi Perencanaan dan Pengendalian Produksi NPK.

Data yang didapatkan dan digunakan untuk analisis lebih lanjut adalah data produksi pupuk NPK subsidi tahun 2015-2017 yang diberikan dari Divisi Perencanaan dan Pengendalian Produksi NPK serta data RKAP (Rencana Kerja dan Anggaran Perusahaan) PT Pupuk Kujang tahun 2018. Sedangkan data sekunder yang didapatkan untuk penyelesaian artikel ini adalah dengan menelaah data RKAP tahun 2016-2017 yang berasal dari Laporan Tahunan PT Pupuk Kujang tahun 2016 dan data laba bersih 2017 yang berasal dari Laporan Tahun PT Pupuk Kujang tahun 2017. Selanjutnya, analisa data dilakukan dengan menggunakan dua metode forecasting: The Winters Exponential Smoothing dan Simple Moving Average . Hasil dari analisis tersebut digunakan untuk menentukan scheduling produksi pupuk NPK PT Pupuk Kujang di masa mendatang. Untuk menilai kecocokan metode Simple Moving Average dalam memprediksi produksi per bulan perusahaan, nilai moneter dari simpangan proyeksi dengan aktual produksi akan dibandingkan dengan laba bersih 2017. 


\section{ANALISIS DATA}

Melalui wawancara dan kunjungan lapangan yang telah dilakukan ke PT Pupuk Kujang, satu masalah utama yang masih menjadi perhatian dari divisi perencanaan dan pengendalian produksi NPK yaitu gudang tidak dapat menampung pupuk NPK yang diproduksi sehingga pupuk NPK terpaksa disimpan di dalam gudang dengan 40 tumpukan. Tumpukan yang ideal atas produk NPK adalah 18-25 tumpukan, seperti yang dapat dilihat pada Gambar 1. Penumpukan yang berlebih ini mengakibatkan 20\% - 30\% produk rusak dan harus dilakukan rework. Masalah ini timbul karena kapasitas gudang bersifat fixed sedangkan penyerapan pupuk dari distributor bersifat musiman. Penyerapan pupuk sangat bergantung oleh musim tanam petani yang juga bersifat tidak pasti karena dipengaruhi faktor cuaca yang tidak bisa dikontrol oleh manusia.

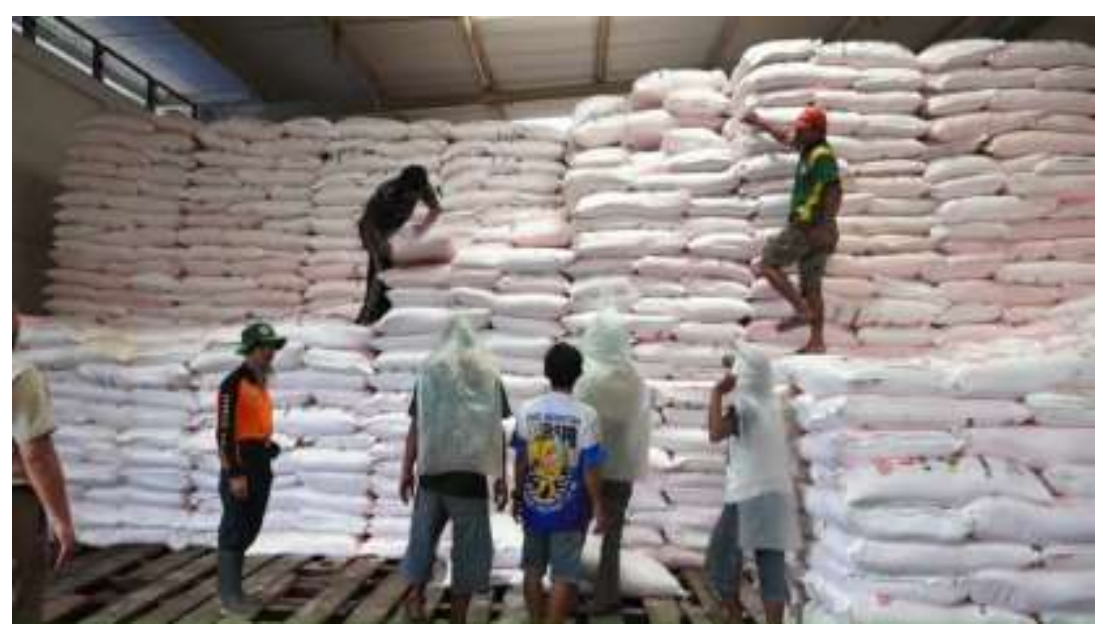

Gambar 1. Kondisi Ideal Penyimpanan Pupuk NPK

Sumber: Sumardiyani (2017)

Isu penumpukan pupuk NPK ini saling berhubungan dengan telah diterapkan PT Pupuk Kujang. Untuk menerapkan production schedulling yang production scheduling, divisi perencanaan dan pengendalian NPK akan berkoordinasi dengan divisi pemasaran. Rapat koordinasi tersebut dilakukan setiap minggu untuk memastikan balansitas produksi dan kesanggupan pemenuhan permintaan kebutuhan NPK dari divisi pemasaran. Selain permintaan kebutuhan dari divisi pemasaran, divisi perencanaan dan pengendalian NPK juga 
mempertimbangkan stok bahan baku yang ada di gudang penyimpanan. Jika bahan baku yang termasuk kategori long delivery part habis, divisi perencanaan dan pengendalian dapat membuat memo percepatan pembelian ke divisi purchasing. Namun, penggunaan memo percepatan ini hanya dilakukan pada kondisi mendesak karena dengan adanya urgent request mengakibatkan harga raw material pun meningkat sehingga harga pokok produksi barang juga meningkat. Untuk mengatasi masalah penumpukan pupuk NPK, perusahaan akan membangun gudang lini IV. Namun, pembangunan gudang lini IV ini masih dalam pembahasan level stratejik perusahaan dan memerlukan waktu lebih dari satu tahun untuk realisasi pembangunannya.

Atas masalah yang didapat pada PT Pupuk Kujang, metode forecasting dapat digunakan agar tidak terjadi kesalahan dalam rencana produksi, sehingga tidak menyebabkan adanya penumpukan pada gudang perusahaan. Sebelum melakukan forecasting, kami akan melihat trend pattern dari data produksi pupuk NPK subsidi pada Diagram 1.

\section{Diagram 1 - Trend pattern Produksi Pupuk NPK Subsidi PT Pupuk Kujang}

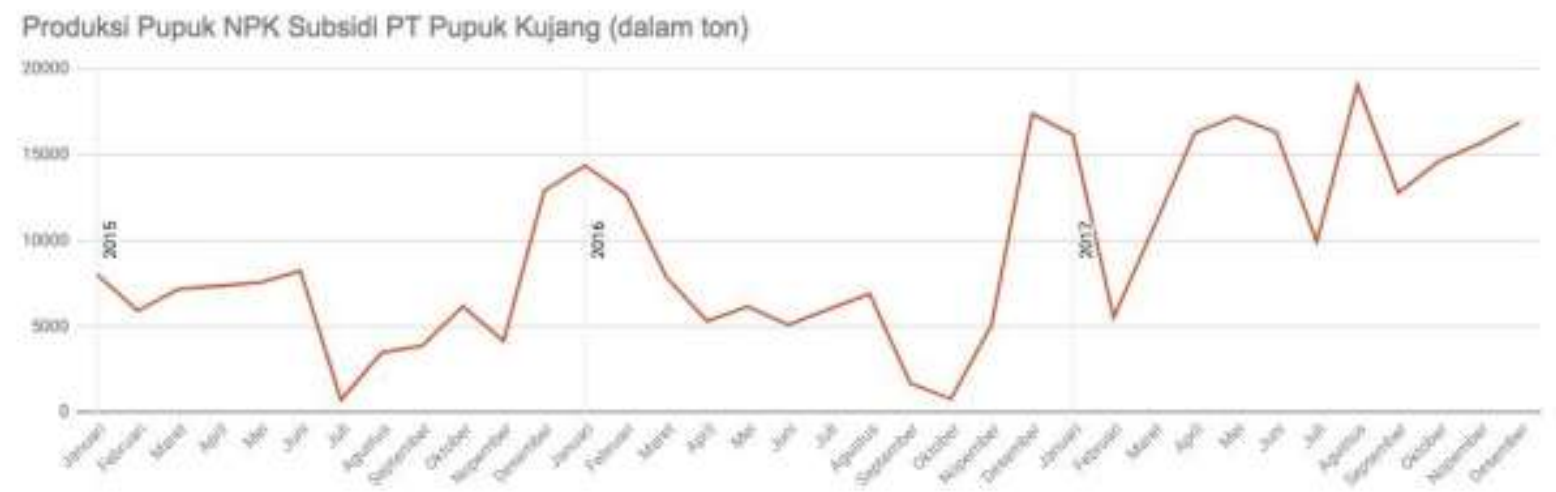

Pada data produksi tersebut ditemukan dua outlier, yaitu bulan Juli 2015 dan bulan Oktober 2016. Pada bulan Juli 2015, perusahaan hanya memproduksi pupuk NPK subsidi sebanyak 728 ton dikarenakan perusahaan menggunakan kapasitas produksinya untuk memproduksi 
pupuk NPK non subsidi sebanyak 4.966 ton, sedangkan pada bulan Oktober 2016 perusahaan hanya memproduksi pupuk NPK subsidi sebanyak 724 ton karena perusahaan juga memproduksi pupuk NPK non subsidi pada bulan tersebut serta terjadi down time (waktu tidak terjadi produksi) pada pabrik untuk perbaikan alat, cleaning area, serta formula treaming untuk produk pupuk non subsidi.

Winters's Exponential Smoothing Method digunakan untuk melakukan forecasting atas produk pupuk NPK subsidi karena produk pupuk bersifat musiman . Kebutuhan pupuk sangat dipengaruhi siklus musim tanam padi. Hasil analisa yang dilakukan untuk forecasting dengan menggunakan data aktual 2015 dapat dilihat pada Tabel 1.

Tabel 1 - Forecasting based on actual data 2015 - Winters Exponential Smoothing Method

\begin{tabular}{rrr} 
based on actual data: & 2015 \\
\hline $\operatorname{sum}\left(x^{*} t\right)$ & $-418,344$ \\
$\operatorname{sum}(x)$ & 75,499 \\
a0 & 6,172 \\
bo & -22
\end{tabular}

\begin{tabular}{|c|r|r|r|r|r|r|}
\hline \multirow{2}{*}{ Month (in ton) } & \multicolumn{3}{|c|}{2016 (in ton) } \\
\cline { 2 - 7 } & $\begin{array}{r}\text { projection } \\
\text { production }\end{array}$ & $\begin{array}{c}\text { actual } \\
\text { production }\end{array}$ & \multicolumn{1}{c|}{ delta } & $\begin{array}{r}\text { projection } \\
\text { production }\end{array}$ & $\begin{array}{c}\text { actual } \\
\text { production }\end{array}$ & \multicolumn{1}{c|}{ delta } \\
\hline 1 & 11,333 & 14,354 & $-3,021$ & 10,854 & 16,144 & $-5,290$ \\
\hline 2 & 8,143 & 12,702 & $-4,559$ & 7,797 & 5,506 & 2,291 \\
\hline 3 & 7,556 & 7,870 & -314 & 7,235 & 10,820 & $-3,585$ \\
\hline 4 & 6,265 & 5,302 & 963 & 5,997 & 16,262 & $-10,265$ \\
\hline 5 & 6,560 & 6,160 & 400 & 6,279 & 17,192 & $-10,913$ \\
\hline 6 & 6,199 & 5,094 & 1,105 & 5,932 & 16,288 & $-10,356$ \\
\hline 7 & 2,613 & 5,996 & $-3,383$ & 2,500 & 9,908 & $-7,408$ \\
\hline 8 & 4,149 & 6,892 & $-2,743$ & 3,969 & 19,042 & $-15,073$ \\
\hline 9 & 2,386 & 1,696 & 690 & 2,282 & 12,770 & $-10,488$ \\
\hline 10 & 3,127 & 784 & 2,343 & 2,991 & 14,596 & $-11,605$ \\
\hline 11 & 3,415 & 5,086 & $-1,671$ & 3,265 & 15,614 & $-12,349$ \\
\hline 12 & 10,813 & 17,356 & $-6,543$ & 10,337 & 16,878 & $-6,541$ \\
\hline Total & 72,560 & 89,292 & $-16,732$ & 69,439 & 171,020 & $-101,581$ \\
\hline & & projection error & $18.74 \%$ & projection error & $59.40 \%$ \\
\hline
\end{tabular}


Pada hasil analisa tersebut didapatkan hasil projection error sebesar 18,74\% untuk forecasting tahun 2016 dan 59,4\% untuk forecasting tahun 2017. Penggunaan Winters's Exponential Smoothing Method dinilai kurang cocok karena kondisi perusahaan atau variabel lain yang mempengaruhi faktor produksi (selain faktor demand pasar) tidak stabil, sebagai contoh pada tahun 2017 pembangunan pabrik NPK granul II sudah selesai sehingga kapasitas produksi meningkat dari 600 ton per hari pada tahun 2016 menjadi 800 ton per hari pada tahun 2017. Penambahan kapasitas produksi ini menyebabkan kondisi ceteris paribus yang menjadi asumsi dasar Winters's Exponential Smoothing Method tidak tercapai.

Berdasarkan data Laporan Tahunan PT Pupuk Kujang tahun 2016 yang didapat dari situs resmi perusahaan, perusahaan melakukan RKAP (Rencana Kerja dan Anggaran Perusahaan) yang menjadi panduan bagi divisi produksi untuk melakukan schedulling. Realisasi penjualan pupuk NPK subsidi pada tahun 2016 dapat dilihat pada Tabel 2.

Tabel 2 - Volume Penjualan Pupuk tahun 2015-2016 PT Pupuk Kujang

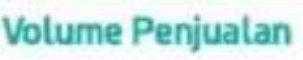

Volume Penjualan Pupuk Tahun 2015-2016

\begin{tabular}{|c|c|c|c|c|c|}
\hline $\begin{array}{l}\text { Uralan } \\
\text { Rempiks }\end{array}$ & $\begin{array}{l}\text { Reallsasl } 2015 \\
\text { Reallowtion in } 2015\end{array}$ & ROCP & $\begin{array}{l}6 . \\
\text { Realiseri } \\
\text { Reothation }\end{array}$ & 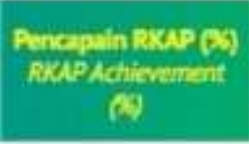 & 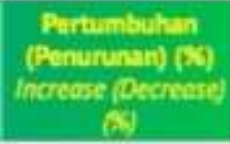 \\
\hline \multicolumn{6}{|c|}{ Penjualan Pupuk Subsidi/Sales of Subsidised Fertilize: } \\
\hline Urea & 484.216 & 632.000 & 640.110 & 101,28 & 32,20 \\
\hline NPK & 45.268 & 165.000 & 94.855 & 57,49 & 109,54 \\
\hline Organik & 43.567 & 66.750 & 24.273 & 36,36 & $(44,29)$ \\
\hline Jumlah & 573.050 & 863,750 & 759.258 & 87,90 & 32,49 \\
\hline
\end{tabular}

Realisasi penjualan tahun 2016 hanya sebesar 57,49\% dari RKAP. Ini dikarenakan pertama, terdapat produk yang kualitasnya kurang baik (kotor, ukuran tidak seragam dan lengket) sehingga PT Pupuk Kujang menarik produk NPK di lapangan yang kualitasnya kurang baik dan digantikan dengan produk NPK yang kualitasnya baik. Kedua, pembagian alokasi NPK 
antara PT Pupuk Kujang dengan PT Petrokimia Gresik kurang jelas yang mana pada kenyataan di lapangan, NPK produksi PT Petrokimia Gresik lebih dominan. PT Pupuk Kujang telah bersikap tegas terhadap Distributor yang kurang peduli terhadap penebusan NPK dengan memberikan sanksi berupa pengurangan wilayah sampai dengan penghentian kerja sama.

Divisi Perencanaan dan Pengendalian Pupuk melakukan schedulling dengan mempertimbangkan angka RKAP penjualan pupuk NPK. Namun, di sisi lain perlu ditekankan bahwa volume produksi juga harus bisa menyesuaikan dengan penyerapan pasar. Untuk mengantisipasi hal tersebut, setiap minggu terdapat meeting yang membahas balansitas produksi dengan minimum stok gudang sarana penjualan.

Metode forecasting sangat bergantung pada data historis, namun akan menjadi sulit ketika terdapat faktor-faktor yang tidak menentu seperti aturan atau regulasi yang banyak berubah. Sebagai contoh, PT Pupuk Kujang mempunyai rencana strategis untuk memenuhi kebutuhan produksi dengan membangun pabrik pupuk NPK Granular III. PT Pupuk Kujang juga harus bersiap menghadapi perubahan pembagian wilayah distribusi yang kerap bersinggungan dengan wilayah distribusi PT Petrokimia Gresik.

Semua metode forecasting sangat bergantung pada data historis masa lalu dan ini akan menjadi sulit ketika perusahaan menggunakan metode forecasting namun faktor-faktor lain dalam produksi tidak konstan. Contoh dari faktor lain yang mempengaruhi produksi adalah PT Pupuk Kujang memiliki rencana strategik untuk kembali memperbesar kapasitas produksi NPK dengan membangun pabrik NPK granular III, perubahan pembagian wilayah untuk produk pupuk NPK subsidi antara PT Pupuk Kujang dengan PT Petrokimia Gresik.

Berdasarkan wawancara yang dilakukan, diketahui bahwa RKAP untuk volume penjualan pada tahun 2018 adalah sebesar 162.000 ton untuk produk pupuk NPK Subsidi. Dengan 
menggunakan simple moving average per dua bulan (dari tahun 2015-2017) maka akan didapatkan percentage of production moving average pada Tabel 3.

Tabel 3 - Simple Moving Average (2 months) - Percentage of Production

\begin{tabular}{|c|c|c|c|c|c|}
\hline Year & Month & Production & $\begin{array}{l}\text { Percentage of } \\
\text { Production }\end{array}$ & $\begin{array}{c}\text { Simple MA (2 months) } \\
\text { - Percentage of } \\
\text { Production }\end{array}$ & $\begin{array}{c}\text { Normalized } \\
\text { Simple MA ( } 2 \text { months) - } \\
\text { Percentage of Production }\end{array}$ \\
\hline \multirow{13}{*}{2016} & Januari & 14,354 & $16.08 \%$ & $11.29 \%$ & $11.57 \%$ \\
\hline & Februari & 12,702 & $14.23 \%$ & $16.57 \%$ & $16.99 \%$ \\
\hline & Maret & 7,870 & $8.81 \%$ & $15.15 \%$ & $15.53 \%$ \\
\hline & April & 5,302 & $5.94 \%$ & $11.52 \%$ & $11.81 \%$ \\
\hline & Mei & 6,160 & $6.90 \%$ & $7.38 \%$ & $7.56 \%$ \\
\hline & Juni & 5,094 & $5.70 \%$ & $6.42 \%$ & $6.58 \%$ \\
\hline & Juli & 5,996 & $6.72 \%$ & $6.30 \%$ & $6.46 \%$ \\
\hline & Agustus & 6,892 & $7.72 \%$ & $6.21 \%$ & $6.37 \%$ \\
\hline & September & 1,696 & $1.90 \%$ & $7.22 \%$ & $7.40 \%$ \\
\hline & Oktober & 784 & $0.88 \%$ & $4.81 \%$ & $4.93 \%$ \\
\hline & Nopember & 5,086 & $5.70 \%$ & $1.39 \%$ & $1.42 \%$ \\
\hline & Desember & 17,356 & $19.44 \%$ & $3.29 \%$ & $3.37 \%$ \\
\hline & Total & 89,292 & $100.00 \%$ & $97.54 \%$ & $100.00 \%$ \\
\hline \multirow{13}{*}{2017} & Januari & 16,144 & $9.44 \%$ & $12.57 \%$ & $11.65 \%$ \\
\hline & Februari & 5,506 & $3.22 \%$ & $14.44 \%$ & $13.39 \%$ \\
\hline & Maret & 10,820 & $6.33 \%$ & $6.33 \%$ & $5.87 \%$ \\
\hline & April & 16,262 & $9.51 \%$ & $4.77 \%$ & $4.43 \%$ \\
\hline & Mei & 17,192 & $10.05 \%$ & $7.92 \%$ & $7.34 \%$ \\
\hline & Juni & 16,288 & $9.52 \%$ & $9.78 \%$ & $9.07 \%$ \\
\hline & Juli & 9,908 & $5.79 \%$ & $9.79 \%$ & $9.08 \%$ \\
\hline & Agustus & 19,042 & $11.13 \%$ & $7.66 \%$ & $7.10 \%$ \\
\hline & September & 12,770 & $7.47 \%$ & $8.46 \%$ & $7.85 \%$ \\
\hline & Oktober & 14,596 & $8.53 \%$ & $9.30 \%$ & $8.62 \%$ \\
\hline & Nopember & 15,614 & $9.13 \%$ & $8.00 \%$ & $7.42 \%$ \\
\hline & Desember & 16,878 & $9.87 \%$ & $8.83 \%$ & $8.19 \%$ \\
\hline & Total & 171,020 & $100.00 \%$ & $107.85 \%$ & $100.00 \%$ \\
\hline
\end{tabular}

Penggunaan simple moving average selama dua bulan untuk meminimalisasi simpangan yang terjadi antara proyeksi dengan aktual dan proyeksi akan lebih mencerminkan produksi yang bersifat musiman dan fluktuatif setiap bulannya. Setelah mendapatkan percentage of production moving average, dilakukan normalisasi agar jumlahnya menjadi $100 \%$. Setelah itu, kami melakukan forecasting untuk tahun 2017, hasil proyeksi untuk tahun 2017 dapat dilihat pada Tabel 4. 
Vol.01, No. 2, 2018

Tabel 4 - Proyeksi, Aktual dan Simpangan Produksi tahun 2017

\begin{tabular}{|c|c|c|c|c|c|}
\hline Year & Month & \begin{tabular}{|c|} 
Normalized \\
Simple MA ( 2 months) \\
- Percentage of \\
Production
\end{tabular} & $\begin{array}{c}\text { Projection } \\
\text { Production (in } \\
\text { ton) }\end{array}$ & $\begin{array}{c}\text { Actual Production (in } \\
\text { ton) }\end{array}$ & Delta \\
\hline \multirow{13}{*}{2017} & Januari & $11.57 \%$ & 19,091 & 16,144 & 2,947 \\
\hline & Februari & $16.99 \%$ & 28,039 & 5,506 & 22,533 \\
\hline & Maret & $15.53 \%$ & 25,629 & 10,820 & 14,809 \\
\hline & April & $11.81 \%$ & 19,487 & 16,262 & 3,225 \\
\hline & Mei & $7.56 \%$ & 12,477 & 17,192 & $-4,715$ \\
\hline & Juni & $6.58 \%$ & 10,858 & 16,288 & $-5,430$ \\
\hline & Juli & $6.46 \%$ & 10,660 & 9,908 & 752 \\
\hline & Agustus & $6.37 \%$ & 10,505 & 19,042 & $-8,537$ \\
\hline & September & $7.40 \%$ & 12,208 & 12,770 & .562 \\
\hline & Oktober & $4.93 \%$ & 8,135 & 14,596 & $-6,461$ \\
\hline & Nopember & $1.42 \%$ & 2,349 & 15,614 & $-13,265$ \\
\hline & Desember & $3.37 \%$ & 5,560 & 16,878 & $-11,318$ \\
\hline & Total & $100.00 \%$ & 165,000 & 171,020 & $-6,020$ \\
\hline
\end{tabular}

Simpangan atau MAPE yang terjadi antara proyeksi dengan aktual adalah sebesar 3,52\%. Ketika nilai simpangan berada dibawah $25 \%$, maka dengan menggunakan metode simple moving average, hasil data yang diramalkan dapat diterima dengan memuaskan. Selain itu, hasil simpangan dengan metode ini $(3,52 \%)$ lebih kecil jika dibandingkan dengan hasil simpangan dengan metode The Winter's (59,40\%). Maka dari itu metode simple moving average lebih sesuai digunakan pada forecasting produksi pupuk PT Pupuk Kujang.

Untuk penelitian selanjutnya, analisis menggunakan metode analisis dan proyeksi deret berkala lainnya seperti Box-Jenkins dan X-11 dapat dilakukan, sehingga hasil forecasting yang didapat menjadi lebih akurat. Metode-metode tersebut sebaiknya dilakukan apabila data historis produksi yang didapat mencapai lebih dari lima tahun. Pada penelitian ini, hal tersebut tidak dilakukan karena adanya keterbatasan informasi yang didapat dari PT Pupuk Kujang. Jika penjadwalan proses produksi pada PT Pupuk Kujang sudah dapat berjalan dengan lancar dan tidak menyebabkan penumpukan, maka PT Pupuk Kujang dapat menerapkan 
Vol.01, No. 2, 2018

sistem manajemen penyimpanan pestisida dan pupuk yang baik menurut

Waskom dan Yergert (1994).

\section{KESIMPULAN}

Berdasarkan hasil analisis yang telah kami lakukan, metode yang paling cocok dipakai oleh PT Pupuk Kujang untuk menyelesaikan masalah penumpukan produk jadi pada inventori perusahaan adalah metode simple moving average.

\section{Tabel 5 - Proyeksi Produksi tahun 2018}

RKAP 2018
\begin{tabular}{|l|r|r|}
\hline \multicolumn{1}{|c|}{ Months } & $\begin{array}{c}\text { Normalized } \\
\text { Simple MA (2 months) } \\
\text { - Percentage of } \\
\text { Production }\end{array}$ & $\begin{array}{c}\text { Projection } \\
\text { (in ton) }\end{array}$ \\
\hline Januari & $11.65 \%$ & 18,643 \\
\hline Februari & $13.39 \%$ & 21,420 \\
\hline Maret & $5.87 \%$ & 9,390 \\
\hline April & $4.43 \%$ & 7,081 \\
\hline Mei & $7.34 \%$ & 11,746 \\
\hline Juni & $9.07 \%$ & 14,510 \\
\hline Juli & $9.08 \%$ & 14,521 \\
\hline Agustus & $7.10 \%$ & 11,362 \\
\hline September & $7.85 \%$ & 12,556 \\
\hline Oktober & $8.62 \%$ & 13,798 \\
\hline Nopember & $7.42 \%$ & 11,869 \\
\hline Desember & $8.19 \%$ & 13,103 \\
\hline Total & $100.00 \%$ & 160,000 \\
\hline
\end{tabular}

Dengan adanya RKAP tahun 2018 dengan jumlah produksi sebesar 160.000 ton, maka kami memberikan solusi kepada perusahaan untuk melakukan produksi pada tahun 2018 seperti pada Tabel 5. Tentunya masalah penumpukan produk NPK tidak hanya disebabkan oleh schedulling yang kurang tepat tetapi ada faktor lainnya yang saling berkorelasi, yaitu penambahan kapasitas pabrik atau mesin tanpa diimbangi dengan penambahan kapasitas gudang penyimpanan. 


\section{DAFTAR PUSTAKA}

Aprilia D. (2016), "Penerapan Metode Forecast Exponential Smoothing pada Jumlah Pasien Puskesmas”, Jurnal Biometrika dan Kependudukan 5, No. 2 (Desember): 146-156.

Ariyanto R., Puspitasari D., dan Ericawati F. (2017), "Penerapan Metode Double Exponential Smoothing pada Peramalan Produksi Tanaman Pangan", Jurnal Informatika Polinema 4, No. 1 (November): 57-62.

Chambers J. C., Mullick S. K., and Smith D. D. (1971), "How to Choose the Right Forecasting Technique", Harvard Business Review (July).

Ellis C. A. and Parbery S. A. (2005), "Is smarter better? A comparison of adaptive, and simple moving average trading strategies", Research in International Business and Finance 19, No. 3: 399-411.

Jain C. L. and Malehorn J. (2006), Benchmarking Forecasting Practices: A Guide to Improving Forecasting Performance 3 ed., Graceway Publishing Company Inc., New York.

Mainassy A. K. (2014), “Analisis dan Peramalan Produksi Tanaman Teh dengan Menggunakan Metode Indeks Musim: studi kasus Propinsi Jawa Barat”, Universitas Kristen Satya Wacana, Indonesia.

Montgomery D. C., Jennings C. L., and Kulahci, M. (2008), Introduction To Time Series Analysis and Forecasting, Wiley Interscience, United States of America.

Nahmias, Steven dan Olsen, Tava L. (2015), $\quad$ Production and Operation Analysis, $\quad 7$ th ed., Waveland Press, United States of America.

Raihan, Eff M. S., dan Hendrawan A. (2016), "Forecasting Model Exponential Smoothing Time Series Rata Rata Mechanical Availability Unit Off Highway Truck Cat 777d Caterpillar", Jurnal Poros Teknik 8, No. 1 (Juni): 1-54.

Slack N., Brandon-Jones A., and Johnston R. (2013), $\quad$ Operation Management, 7th ed., Pearson, United Kingdom.

Sumardiyani W. R. (2017), Jangan Tergiur Pupuk Murah, Ini Alasannya , Pikiran Rakyat Website, https://www.pikiran-rakyat.com/, (10 Agustus 2018).

Waskom R. M. dan Yergert M. D. (1994), Best Management for Pesticide and Fertilizer Storage and Handling , Colorado State University Cooperative Extension, August 1994, Buletin \#XCM-178. 